\title{
Pandemia, confinamiento e impresión 3D
}

\author{
Á. D. Martín-Blas Cifuentes
}

Tras la declaración oficial de la pandemia el 11 de marzo de 2020 por parte de la OMS, en España se inicia una etapa marcada por el confinamiento, la escasez de recursos relacionados con los equipos de protección individual (EPI), la incertidumbre y la preocupación. En ese mismo instante, el Grupo Social ONCE puso en marcha, inmediatamente, una serie de medidas encaminadas a proporcionar recursos y ayuda a todo el colectivo de la discapacidad.

A la vez que nos veíamos obligados a iniciar un confinamiento muy duro, teníamos noticias de que se estaba creando una red solidaria de constructores (coronamakers) en toda España con el objetivo de realizar respiradores, protecciones y otros accesorios para hospitales y personal sanitario ante su gran demanda y absoluta escasez en el mercado.

Como parte de esa iniciativa, en el Grupo Social ONCE, varias entidades, centros y personas nos sumamos a esa red de coronamakers aportando los recursos materiales y tecnológicos disponibles. La Fundación ONCE, el Centro de Tiflotecnología e Innovación (CTI) y el Servicio Bibliográfico de la ONCE (SBO) aportamos equipos, personal y material para tan importante labor.

Yo soy técnico del SBO y, entre otros trabajos que realizamos en nuestro día a día, llevamos unos años fabricando piezas en 3D que les permiten un acercamiento excepcional al mundo del arte, la arquitectura y la cultura a nuestros afiliados y usuarios. Utilizando esa experiencia y las cuatro impresoras con las que contamos en el SBO, pensé que lo mejor sería llevarme dichas impresoras a mi domicilio y fabricar a un ritmo constante los materiales que se nos solicitaban (Figura 1). Dicho y hecho: cargué con las cuatro impresoras y el material necesario, y convertí el salón de mi casa en un taller de fabricación 3D. 
Figura 1. El salón de una mi casa convertido en una mesa-taller doméstica 3D

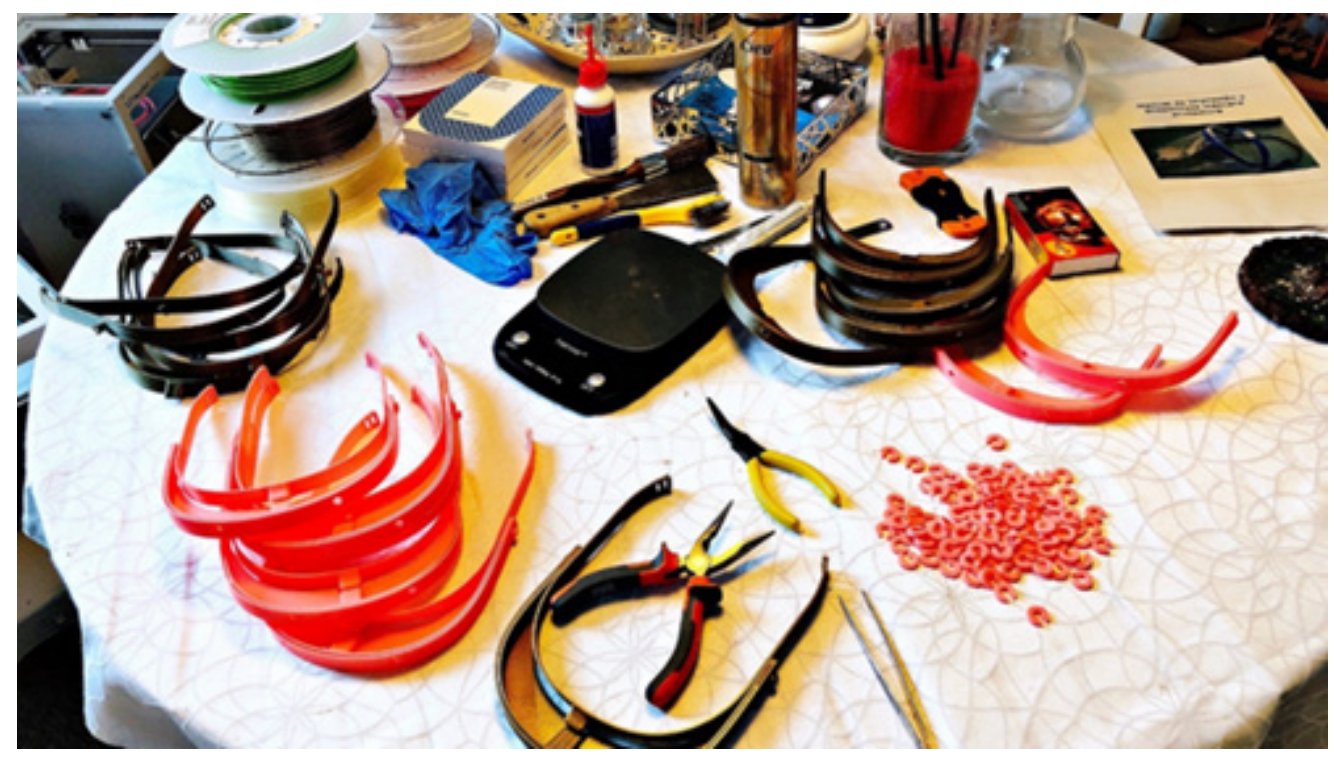

Con las impresoras funcionando casi las 24 horas, pude aportar al proyecto más de 400 pantallas protectoras y más de 2000 salvaorejas para mascarillas. Todo se fabricó en el material más habitual de impresión 3D, el PLA, un tipo de plástico fundente cuya base es el maíz. Desde el grupo de coordinación, me llegaban al correo electrónico los mensajes con los archivos necesarios para poder imprimir las piezas. Archivos verificados y homologados que habían sido previamente diseñados por ingenieros voluntarios conocedores de los materiales que hacían falta para su distribución, según su escasez e importancia. A veces, estos archivos - como, por ejemplo, las máscaras protectoras - recibían varias actualizaciones tras comprobar que había algún fallo en el diseño y/o la fabricación. Al final, tras muchas pruebas, los archivos definitivos dieron el resultado buscado.

El día a día era bastante rutinario: fabricación de piezas, recortado, lijado, ensamblado, empaquetado y vuelta a dejar por la noche las impresoras funcionando para tener más piezas listas por la mañana. Esa rutina me hizo pasar de una forma mucho más amena el confinamiento. Las muestras de apoyo y cariño de compañeros y amigos eran constantes e incluso el trabajo tuvo su eco en la prensa. Cada varios días, siempre coordinados desde la Fundación ONCE, compañeros de la Fundación y otros voluntarios venían a mi casa a recoger el fruto de mi trabajo y a traer material nuevo con el que seguir fabricando. La red de coronamakers era muy grande y exigió una logística y coordinación notables. 
Fueron dos meses muy intensos de duro trabajo, pero muy gratificantes, sabiendo que los destinatarios finales de esas máscaras y protectores tendrían los equipos necesarios para poder trabajar sin riesgo de contagio.

Ángel David Martín-Blas Cifuentes. Técnico de Servicios Bibliográficos. Sección de Relieves. Servicio Bibliográfico de la ONCE. La Coruña, 18; 28020 Madrid (España). Correo electrónico: admc@once.es. 